\title{
Prevalence of Risk Factors of Noncommunicable Diseases in 12 Barangays of the AMIGA Municipalities of Cavite
}

\author{
Elizabeth R. Paterno \\ Department of Family and Community Medicine, College of Medicine and Philippine General Hospital, University of the Philippines Manila
}

\begin{abstract}
Objective. This study aims to determine the prevalence of risk factors of non-communicable diseases (NCDs) in 16 barangays of the AMIGA municipalities of Cavite.

Methods. The research is a cross-sectional study. Randomly chosen participants were interviewed using a translated version of the WHO Steps questionnaire. Interviewees were then invited to participate in another session where their anthropometric measurements were taken and their fasting blood sugar and cholesterol levels were determined.

Results. The research was done in 12 out of the 16 targeted barangays. A total of 1,527 participants were interviewed and 1,123 of them completed the study. The most significant findings in all 12 barangays were a very high rate of passive smoking (range of 60-80\%); a relatively high proportion of respondents with obesity by all 3 parameters (BMI 29-52\%; waist circumference 42-78\%; and waist-to-hip ratio 41-78\%) despite sufficient intake of fruits and vegetables and more than adequate physical activity; and a high proportion of participants with hypertension (more than $30 \%$ in 8 out of 12 barangays) and diabetes mellitus (more than $8 \%$ in 7 out of 12 barangays).
\end{abstract}

Conclusion. A high prevalence of risk factors of NCDs, particularly obesity, hypertension, and diabetes was found in the 12 barangays of AMIGA that participated in the study. Results of this study should provide the baseline data against which the success of an ongoing program in the area can be measured.

Key Words: noncommunicable disease risk factors, WHO Steps questionnaire, AMIGA municipalities of Cavite

\section{INTRODUCTION}

There is a global call to scale up efforts to prevent and control non-communicable diseases (NCDs) such as cardiovascular disease, cancer, diabetes and chronic lung diseases as these have overtaken infectious diseases as the leading causes of mortality worldwide. The World Health Organization (WHO) reported an increase in the proportion of deaths from NCDs out of the total global deaths from 38 million or $68 \%$ of the 56 million deaths in 2012 to 40.4 million or $71 \%$ out of 56.9 million in $2016.46 \%$ of these deaths from NCDs in 2016 were premature deaths under 70 years of age, an increase from $40 \%$ in 2012. Majority of premature deaths $(82 \%)$ occur in low and middle-income countries ${ }^{1,2} \mathrm{NCD}$ are major public health issues in almost all countries of the Western Pacific Region of the WHO, where

Corresponding author: Elizabeth R. Paterno, MD, MPH Department of Family and Community Medicine Philippine General Hospital University of the Philippines Manila Taft Avenue, Manila 1000, Philippines Email: bebolrp@gmail.com the poor have the worst outcomes from these diseases. ${ }^{3}$ In the Philippines, cardiovascular diseases (CVD) account for 33\% of all deaths, while another $6 \%$ is due to diabetes mellitus. ${ }^{4}$ Diseases of the heart and diseases of the vascular system ranked first and second respectively among the top 10 causes 
of mortality in the country from 2012-2014, while diabetes mellitus increased rank from the $7^{\text {th }}$ cause of mortality in 2012 to the $6^{\text {th }}$ in 2013 and 2014. ${ }^{\text {a }}$ Hypertension consistently ranked third among the top 10 causes of morbidity from 2012-2014. ${ }^{5}$ The Food and Nutrition Research Institute (FNRI) of the Department of Science and Technology concluded in its report on the $8^{\text {th }}$ National Nutrition Survey conducted in 2013 that there was indeed an increase in the prevalence of risk factors indicative of the increase in the burden of NCDs in the country. For instance, over the past decade, the prevalence of high fasting blood glucose has risen steadily from $3.4 \%$ in 2003 to $5.6 \%$ in 2013; and the prevalence of high waist circumference and high waist-tohip ratio which are indicative of central or android obesity also increased from $19.9 \%$ and $62.5 \%$ respectively in 2011 to $23.1 \%$ and $63.2 \%$ in $2013 .{ }^{6}$

In 2002, the WHO initiated the STEPwise approach to surveillance (STEPS) in recognition of the global need for NCD risk-factor data. The STEPS is a simple method of collecting, analyzing and reporting data for WHO member countries. It was used as early as 2001 in Fiji and was last updated by the WHO in 2008. By 2016, the STEPS had been used by 122 countries in all 6 regions of the WHO. ${ }^{7}$ Locally, it was used by the FNRI in its $8^{\text {th }}$ National Nutrition Survey in 2013. ${ }^{6}$ The STEPS approach is a sequential process and is presented in seven modules. The first step utilizes a questionnaire, then moves on to simple physical measurements (Step 2). It is only in Step 3 where the collection of blood samples for biochemical assessment is done. The main risk factors that are targeted for measurement are grouped into the behavioral risk factors (tobacco use, harmful alcohol consumption, unhealthy diet [low fruit and vegetable consumption] and physical inactivity); and the biological risk factors (overweight and obesity, raised blood pressure, raised blood glucose, abnormal blood lipids, and its subset raised total cholesterol).

\section{Study Context}

The University of the Philippines Manila (UPM) through its Community Health and Development Program (UP CHDP) forged a partnership with 5 municipalities of Cavite, collectively called the AMIGA Inter-LGU Health Collaboration Council to initiate a program for the control of hypertension and diabetes. Specifically, the program targeted to increase the proportion of those with controlled disease by $25 \%$ through early identification of the risk factors and proper management of those with disease. AMIGA is an acronym that stands for the first letters of these 5 municipalities: Alfonso, Mendez, Indang, General Emilio Aguinaldo and Amadeo. This study was conceptualized

\footnotetext{
a These are the latest available data from the Department of Health and the Philippine Statistics Authority as of the date of writing of this manuscript.
}

to collect data for the program using the WHO Stepwise approach to NCD surveillance. The results of the study were intended to provide baseline data against which the program outcomes were to be compared at the end of the partnership.

\section{Study objectives}

The study aims to determine the prevalence of obesity, hypertension, raised blood sugar, raised cholesterol, and the behavioral risk factors (smoking, excessive alcohol intake, inadequate fruit and vegetable intake, and lack of physical activity) among adults aged 25-65 years old in the 16 targeted barangays. In addition, the study aims to identify significant correlations between the non-modifiable risk factors (age, sex, and income) with the modifiable risk factors especially smoking, alcohol intake, fruit and vegetable intake and physical activity.

\section{MATERIALS AND METHODS}

\section{Study design and setting}

The research was a cross-sectional study intended to be conducted in sixteen (16) barangays chosen as the pilot areas for program implementation in 2013 by the AMIGA-UP CHDP partnership. Data collection was conducted from October 2016 - September 2017.

\section{Sample size}

The sample size in each barangay was determined to assume a confidence level of $95 \%$ and a margin of error of 5\%. The DOH prevalence estimate of hypertension in 2011 at $24 \%$ was assumed to be true in the $\operatorname{area}^{8}$ and was chosen as the basis of sample size computation. Since the population in each barangay was small, the formula for finite population correction was applied, and it was assumed that $50 \%$ of the target population was within the 25-65 year age range. The total sample size computed for the survey was 3,236 adults. This number is the sum of the computed sample sizes in the 16 barangays.

\section{Sampling method}

In each barangay, the population was stratified according to sitio. The allocation of the sample size for each sitio was proportional to the sitio's population in relation to the total population of the barangay. The list of households in each sitio served as the sampling frame. A random sample of households was taken. All qualified individuals in the sample household were invited to participate in the survey. Selected households where all qualified respondents refused or were unable to participate were replaced by a household taken from the additional reserve list also randomly chosen i.e. $10 \%$ of the computed sample size.

\section{Recruitment of study participants}

Individuals randomly chosen through the method described above were visited in their homes and a participant 
information form was read and subsequently given to him/ her to elicit his/her consent for participation. The ensuing discussion was used to gauge the competence of the participant to provide reliable answers to the survey questions. Inclusion criteria were the following: aged 25-65 years old; was willing to sign an informed consent for participation in the survey; resided in the barangay for at least 4 days a week and 2 weeks a month to ensure their participation in all the 3 steps of the study, and could understand Filipino. Potential participants who had cognitive deficit (e.g. aphasia, dementia, mental disorders like retardation and psychosis) that would inhibit $\mathrm{him} /$ her from providing accurate answers to the survey questions were excluded from the study.

\section{Study Tools}

Relevant WHO STEPS documents (questionnaire, participant information form, informed consent form, patient feedback form $)^{9}$ were translated into Filipino by a member of the Sentro ng Wikang Pilipino of the UPM. Only the core questions on the risk factors were included in the translated questionnaire. The translated versions were piloted in a barangay among twenty (20) community members who were not in the randomized list of households. Unclear statements and questions which elicited inconsistent answers were noted and reformulated. The revised questionnaire was then tried again among other community members likewise not part of the randomized households and subsequently finalized. The final version of the questionnaire, information, and consent forms were eventually approved by the Research Ethics Board of UPM National Institutes of Health. Show cards included in the STEPS module were utilized in the interview augmented with or replaced by (as deemed appropriate) locally developed ones. These documents were approved by the Municipal Health Officers of all 5 AMIGA municipalities and they agreed to be cosignatories of the informed consent forms.

Anthropometric measurements (weight, height, waist, and hip circumferences) were taken using the following equipment: (1) dial type clinic weighing scale; (2) height board; and (3) non-stretch measuring tapes. Blood pressure was taken using an automated $\mathrm{BP}$ measuring device (Omron 7203). Capillary blood sugar and cholesterol were measured with a dry biochemistry device (Accutrend Plus). ${ }^{10}$ Vegetable and fruit intake was measured using standard measuring cups used for cooking. Plastic models of bananas, apples, and oranges with measurements consistent with recommended standard sizes were also used to measure the intake of these fruits.

\section{Data collection}

Data collection was done by trained data collectors following the WHO STEPS Manual. ${ }^{10}$ The first step was the interview of participants using the approved questionnaire. This was usually done in the homes of the participants. At the end of the interview, participants were informed of the schedule of steps 2 and 3 sessions and instructed to fast for 10 hours before the sessions. The second and third steps were done on a single occasion, usually at the barangay health station starting at 6 o'clock in the morning in consideration of the participants' fasting state and to minimize disturbance in the participants' usual working hours. Anthropometric measurements were done following the WHO Steps manual recommendations. ${ }^{\mathrm{b}}$ Blood pressure $(\mathrm{BP})$ was taken in the seated position with both feet flat on the floor after the participants had been resting for 15 minutes. BP was taken three times, 3 minutes apart. The first measurement was discarded and the mean value of the last two readings was used for analysis. Capillary blood sample was taken at the lateral part of the tip of the $3^{\text {rd }}$ or $4^{\text {th }}$ finger using a lancet. Measurement results were given to the participants at the end of steps 2 and 3 , and participants who were found to have conditions that needed medical attention were managed by senior FCM residents from the Philippine General Hospital who were rotating in the AMIGA municipalities at the time of the sessions.

\section{Description of study outcomes}

Unless otherwise stated, measurement description and cut-offs recommended in the WHO STEPS manual and the DOH Operations manual on the Philippine Package of Essential NCD Interventions (PHILPEN) on the integrated management of hypertension and diabetes for primary health care facilities were used in the study. ${ }^{10,11}$

\section{Tobacco use}

Participants were classified as current users (both daily and non-daily users), non-current users, and those who never used tobacco. Among current users, the mean duration of tobacco use, mean age of initiation and mean amount of tobacco used per day was determined. The number of current smokers who were advised by a medical doctor to stop smoking in the past 12 months as well as the prevalence of passive smokers were likewise described. Passive smoking (or secondhand smoking) is defined as exposure to cigarette, cigar or pipe smoke from another person, without smoking directly. ${ }^{5}$

\section{Alcohol consumption}

Participants were classified as those who drank alcoholic beverages in the 12 months and 30 days prior

\footnotetext{
b Height was measured in centimeters in the standing position with footwear and headwear removed, making sure that the shoulders, buttocks and back of the feet were touching the board, and the head in a position where the angle of the eye was at a level with the top of the ear. Weight was measured in kilograms with footwear removed and pockets emptied. Waist circumference was measured at the end of a normal respiration with both hands at the side at a level midway between the lowest rib and the iliac crest. Hip circumference was taken at the widest diameter around the buttocks.
} 
to the interview and those who had never tried drinking alcoholic beverages (lifetime abstainers). Amount of alcohol consumption was measured in standard drinks, following the standards used by the FNRI in the $8^{\text {th }}$ National Health Survey. ${ }^{6}$ Among those who drank in the past 30 days, the number of hazardous, harmful and binge drinkers were determined. Hazardous drinkers among men were those who drank 3-4.5 standard drinks per occasion, and among women 1.5-3 standard drinks per occasion. Harmful drinkers among men were those who drank more than 4.5 and among women more than 3 standard drinks per occasion. Binge drinkers among men were those who drank more than 5 and among women more than 4 standard drinks per occasion. The mean number of days that drinkers engaged in binge drinking in the past 30 days was also measured.

\section{Diet}

Only vegetable and fruit intake on an average week in the 12 months prior to the interview was measured. The results were described as the mean number of days that fruits were consumed; mean number of days that vegetables were consumed; and the mean number of combined servings of fruits and vegetables consumed on an average day. Consumption of a minimum of 5 servings of combined vegetables and fruits every day was deemed sufficient to prevent diseases like cardiovascular diseases, cancer, diabetes, obesity, and other micronutrient deficiencies. ${ }^{6}$

\section{Physical Activity}

Both work and recreational activities were measured and both of these activities were classified as either moderate or vigorous. Classification of activities followed the WHO Global Physical Activity Questionnaire: Analysis Guide. ${ }^{12}$ Walking or bicycling to and from places was considered as moderate activity and was included in the measurement. Only activities that were done continuously for 10 minutes were counted. Each minute of moderate activity was considered equivalent to 4 metabolic equivalent units or MET minutes, while each minute of vigorous activity was counted as 8 MET minutes. 600 MET minutes per week were deemed adequate; those who did not meet this cut off were counted as physically inactive.

\section{Hypertension/Diabetes Mellitus}

Participants who had been previously diagnosed as hypertensive and on regular medication regardless of the results of BP measurement, as well as participants who were not previously diagnosed as hypertensive but whose BP measurements during the step 2 session exceeded the recommended cut-offs were counted as hypertensive. Participants who were previously told they had hypertension, were not taking meds and had normal BP measurements were not counted as hypertensive. BP measurement cutoffs followed the recommendations in the $7^{\text {th }}$ and $8^{\text {th }}$ reports of the US Joint National Committee on Prevention,
Detection, Evaluation, and Treatment of High Blood Pressure (JNC7 and JNC8). ${ }^{13,14}$ Systolic BP measurement cut off for adults younger than 60 years old was $\geq 140 \mathrm{mmHg}$ and for those 60 years old or older $\geq 150 \mathrm{mmHg}$. The same diastolic BP measurement cut off at $\geq 90 \mathrm{mmHg}$ was used for both age groups. Similarly, participants who had been previously diagnosed as diabetic and on regular medication regardless of the results of CBG measurement, as well as participants who were not previously diagnosed as diabetic but whose CBG measurement during the step 3 session was $\geq 126 \mathrm{mg} / \mathrm{dL}$ were counted as diabetic. Likewise, those who had been previously told they were diabetic, were not taking medication and had normal fasting CBG levels were not counted as diabetic. Those who were not able to join a step 3 session and had never been told that they were diabetic were presumed not to have diabetes.

\section{Obesity}

Body mass index (BMI) was calculated in weight in $\mathrm{kg}$ over height in $\mathrm{m}^{2}$ and participants were classified as obese if the BMI was $\geq 25 \mathrm{~kg} / \mathrm{m}^{2}$ following the manual of operations for PhilPEN. Central or abdominal obesity was defined as follows: for women $W C \geq 80 \mathrm{~cm}$, waist to hip ratio $(\mathrm{WHR}) \geq 0.85$; for men $\mathrm{WC} \geq 90 \mathrm{~cm}, \mathrm{WHR} \geq 1$.

\section{Cholesterol}

Hypercholesterolemia was defined as cholesterol level $\geq 240 \mathrm{mg} / \mathrm{dL}$.

\section{Statistical analysis}

Variables were expressed as means and frequencies with standard deviation. Overall means and frequencies for the 12 barangays were weighted according to the population size of the barangay. Continuous and categorical variables were compared using Independent samples t-test, Chi-square test or Fisher's exact test, respectively. Confidence interval was set at $95 \%$.

\section{Ethical considerations}

This study was guided by the UPM Research Ethics Board (UPMREB) Guidelines for health researches. This research including the collection tools and the participant information and informed consent forms were approved by the UPM REB (2014-443-01). All potential respondents were oriented on the objectives of the study, including its benefits and risks, and their participation was strictly voluntary. They were advised that they could withdraw from the study at any point in time without any effect on their access to health care services. All individual data were treated with confidentiality, and without direct attribution to the respondents. Data were analyzed and presented in aggregate. Contact details of the study proponents, the UPMREB Chairperson and the UP REB secretariat were provided to all respondents for any concern regarding the study. 


\section{RESULTS}

The research team was able to conduct the study in only 12 out of the targeted 16 barangays. A total of 1,527 individuals (47.2\% of target) were interviewed (step 1). The mean response rate in the 12 barangays was $63.19 \%$ with
the highest at $89.81 \%$ and the lowest at $22.75 \% .1,123$ or the highest at $89.81 \%$ and the lowest at $22.75 \% .1,123$ or $73.54 \%$ of those who were interviewed also participated in
steps 2 and 3 of the study. The main reason for not reaching all of the 16 targeted barangays was the difficulty in finding qualified data gatherers as the original well qualified tound other more permanent jobs in the middle of the study. Participants who were interviewed but could not attend the sessions on anthropometric and clood chemisty mastrements were limited by their work schedule even as the time for these sessions was set at 6 in the morning.
Socio-demographic characteristics

The socio-demographic characteristics of participant in each barangay are shown in Table 1 . In all barangays, the majority of participants were women, ranging from $54 \%$ to $72.73 \%$. The mean age ranged from 43.81 to 48.73 years. The representation in the 4 age groups $(25-34,35-44$ $45-54$ and $55-65)$ was more or less even in all barangays. except in one barangay where the respondents were predominantly elementary school graduates (61.72\%). In barangays 49.66 to $68.75 \%$ were high school graduates. Most respondents were either self-employed (25.00-41.80\%) or homemakers $(17.86-50.77 \%)$. Except in one barangay where the majority (27.34\%) claimed to earn from P122,000 to P188,000 annually, most respondents in all the other barangays claimed 10 ,

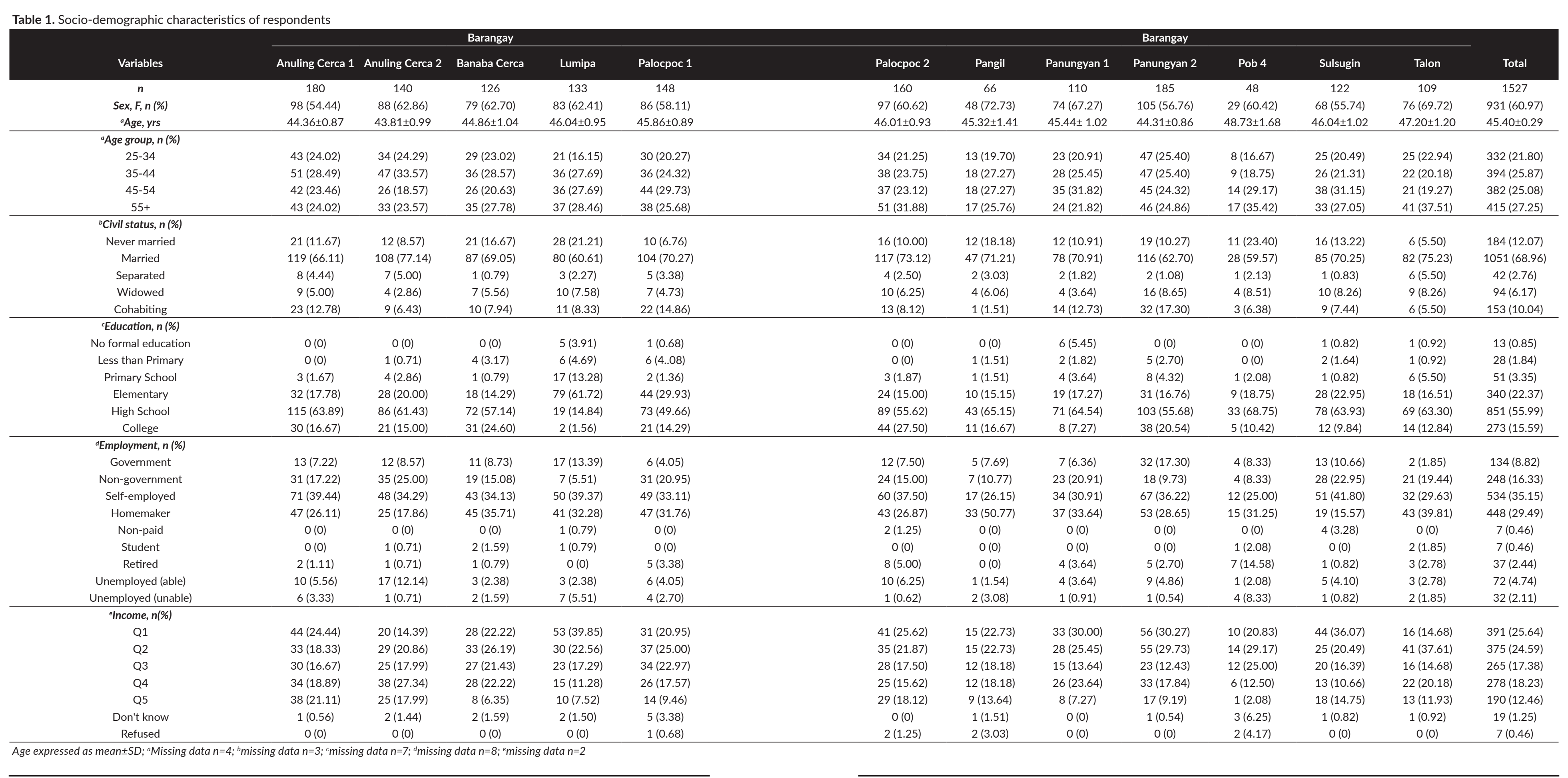


Tobacco use

Across the barangays, from 11.0 to $30.00 \%$ of respondents currently smoked at the time of interview. Of the current smokers, $69.64 \%$ was male. Most $(69.23$ to $100 \%)$ of these current smokers were daily smokers, again mostly male (86.46\%). $73.9 \%$ of non-smokers were female, and females who smoked tended to be non-daily smokers. Daily smokers consumed an average of 12 sticks per day, ranging from 9-14 sticks. The overall mean age of smoking initiation were advised by an MD to stop smoking, while $29.45 \%$ did not visit a physician in the last 12 months. $70.80 \%$ did pasive shows the results of tobacco use in the study barangays.

\section{Alcohol consumption}

From $39.69 \%$ to $63.13 \%$ of respondents drank alcoholic beverages in the last 12 months prior to the interview. $\mathrm{O}$ those who drank in the last 12 months, 25.76 to $43.57 \%$ drank in the last 30 days prior to the interview, and these were mostly male $(77.7 \%) .16 .76-52.08 \%$ of the respondents across the barangays never had alcoholic drinks in their lives (lifetime abstainers), and these were mostly female (81.388.8\%). More than 50\% (52.94-75.00\%) of those who drank in the last 30 days was considered binge drinkers, of which $87.76 \%$ was male. These people indulged in binge drinking for 2-3 days a week. $4.88-28.85 \%$ and $3-12 \%$ were counted as hazardous and harmful drinkers respectively acros

Fruit and vegetable intake

Most respondents ate fruits less than 7 days a week The number of days that participants ate fruits per week ranged from 3 to 4 days across the barangays. Likewise, most respondents ate vegetables less than 7 days a week; the mean number of days that respondents ate vegetables ranged from 4 to 5 days. The mean number of combined fruit and vegetable servings that respondents consumed on an avcrage day ranged from 4 to 6 . The proportion of and veretables on an averae day was $52.74 \%$.

Physical activity

Across the barangays, most respondents were found to be physically active. A proportion of more than $20 \%$ of only two barangays (31.08\% and 21.80\%) In most barangays, the proportion of those physically inactive was less than 15\%, with the lowest at $4.54 \%$. The mean metabolic equivalent units (MET) ranged from 3115 to 9867 MET per week across the barangays.

Hypertension

A relatively high proportion of respondents was found to be hypertensive by history and/or by BP compared to the national average. The proportion ranged from $20.71 \%$ to $45.87 \%$ across the barangays. $84 \%$ of those labeled as hypertensive was previously diagnosed but only $45.45-$ them also had diabetes mellitus. The average systolic BP across the barangays ranged from $117.44-126.67 \mathrm{mmHg}$. The mean diastolic BP was $77.18-83.58 \mathrm{mmHg}$. Table 3 shows the results of hypertensio

Diabetes Mellitus

Please refer to Table 4 for the tabulated results. Similarly, a relatively high proportion of respondents was found to have diabetes mellitus both by history and/or by fasting capillary blood glucose measurement. The mean proportion from $214-18.75 \%$. dround $68 \%$ of these diabetics, like the hypertensives, were previously dingosed and a le on medication. The mean fasting CBC and already 79-91 $\mathrm{m} / \mathrm{dl}$. The proportion of participants with fasting $\mathrm{CBG}>126 \mathrm{mg} / \mathrm{dL}$ ranged from $2-10 \%$ while it was $6-18.6 \%$ for those with fasting CBG of $\geq 100-125 \mathrm{mg} / \mathrm{dL}$

Obesity

A total of 484 respondents out of 1,122 was found to have a BMI of $\geq 25 \mathrm{~kg} / \mathrm{m}^{2}$ or obese (range of $29.03-51.59 \%$ ). $77.30 \%$ of those seen to be obese were women. 34.43-62.50\% was found to be obese by waist circumference, again mostly women; while $41.67-78.12 \%$ by waist-to-hip ratio.

Hypercholesterolemia

Across the barangays, $8.49-28.12 \%$ of participants was found to have blood cholesterol levels of $\geq 240 \mathrm{mg} / \mathrm{dL}$, while $35.20-60.66 \%$ had cholesterol levels of $\geq 200 \mathrm{mg} / \mathrm{dL}-239$ $\mathrm{mg} / \mathrm{dL}$. Tabulated results on both obesity and cholestero levels are shown in Table 5 .
Correlation between non-modifiable factors (age, sex, and income) and modifiable factors (smoking, alcohol intake, fruit and vegetable intake and physical activity) It was only in tobacco use where significant correlations were found with all the non-modifiable factors. There were significantly more current smokers among the males and they tended to belong to the younger age group (25-34 years while higher income earners tended to be nonokers, Alcohol intake was significantly associated only with where current drinkers and binge drinkers were significantly orrelated with the male sex; while significantly more females were lifetime alcohol abstainers. There was no correlation seen between physical activity and the nonmodifiable factors. Fruit and vegetable intake only correlated again with sex, where it was seen that significantly more males were able to eat the recommended 5 servings of combined fruit and veretables per day compared to women.

\section{DISCUSSION AND RECOMMENDATIONS}

In order to contextualize this study within the national situation, the results were compared to the 2015 FNRI Clinical and Health Survey. ${ }^{15}$ The 2015 version, however, did not include blood chemistry measurements, in which case research results were compared with the more comprehensive 2013 version. Like our study, the FNRI surveys used the WHO STEPS questionnair. The outcome parameters and defniterns wese very similar. But, though muth of the results of our study was comparable to the results of the

Table 2. Status of smoking and tobacco use among the respondents

\begin{tabular}{|c|c|c|c|c|c|c|c|c|c|c|c|c|c|}
\hline \multirow{3}{*}{ Risk factor } & \multirow{3}{*}{$\mathrm{N}$} & \multicolumn{5}{|c|}{ Barangay } & \multicolumn{7}{|c|}{ Barangay } \\
\hline & & Anuling Cerca 1 & Anuling Cerca 2 & Banaba Cerca & Lumipa & Palocpoc 1 & Palocpoc 2 & Pangil & Panungyan 1 & Panungyan 2 & Pob 4 & Sulsugin & Talon \\
\hline & & 180 & 140 & 126 & 132 & 148 & 160 & 66 & 110 & 185 & 48 & 122 & 109 \\
\hline \multirow{3}{*}{${ }^{a}$ Current smoker } & $n(\%)$ & $54(30.00)$ & $32(22.86)$ & $26(20.63)$ & $36(27.27)$ & $35(23.65)$ & $33(20.62)$ & $13(19.70)$ & $23(20.91)$ & $45(24.32)$ & $8(16.67)$ & $27(22.13)$ & $12(11.01)$ \\
\hline & $95 \% \mathrm{Cl}$ & 23.30 & 15.90 & 13.57 & 19.67 & 16.80 & 14.35 & 10.10 & 13.31 & 18.14 & 6.12 & 14.76 & 5.13 \\
\hline & $95 \% \mathrm{Cl}$ & 36.69 & 29.81 & 27.70 & 34.87 & 30.49 & 26.89 & 29.29 & 28.51 & 30.51 & 27.21 & 29.5 & 16.88 \\
\hline \multirow{3}{*}{$\begin{array}{l}\text { Daily smokers among } \\
\text { current smokers }\end{array}$} & $n(\%)$ & 44 (81.48) & 29 (90.62) & 20 (76.92) & 31 (86.11) & $28(80.00)$ & $26(78.79)$ & 9 (69.23) & $21(91.30)$ & $42(93.33)$ & $8(100)$ & $20(74.07)$ & $10(83.33)$ \\
\hline & $95 \% \mathrm{Cl}$ & 71.12 & 80.53 & 60.73 & 74.81 & 66.75 & 64.84 & 44.14 & 79.79 & 86.04 & 100 & 57.54 & 62.25 \\
\hline & $95 \% \mathrm{Cl}$ & 91.84 & 100.72 & 93.13 & 97.41 & 93.25 & 92.74 & 94.32 & 102.82 & 100.62 & 100 & 90.6 & 104.42 \\
\hline \multirow{3}{*}{${ }^{a}$ Passive smoker } & $n(\%)$ & $123(68.33)$ & $95(67.86)$ & 91 (72.22) & $91(68.94)$ & $110(74.32)$ & $128(80.00)$ & $43(65.15)$ & $73(66.36)$ & 146 (78.92) & 38 (79.17) & $79(64.75)$ & $65(59.63)$ \\
\hline & $95 \% \mathrm{Cl}$ & 61.54 & 60.12 & 64.4 & 61.04 & 67.29 & 73.8 & 53.66 & 57.53 & 73.04 & 67.68 & 56.28 & 50.42 \\
\hline & $95 \% \mathrm{Cl}$ & 75.13 & 75.59 & 80.04 & 76.83 & 81.36 & 86.2 & 76.65 & 75.19 & 84.8 & 90.66 & 73.23 & 68.84 \\
\hline \multirow{2}{*}{ 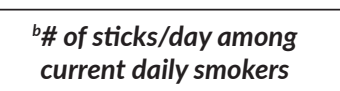 } & Mean & 12.72 & 11.55 & 14.30 & 13.77 & 13.00 & 12.88 & 12.67 & 12.05 & 13.86 & 11.57 & 10.40 & 9.50 \\
\hline & SD & 8.34 & 6.37 & 10.23 & 8.54 & 5.85 & 9.3 & 8.17 & 6.35 & 11.6 & 6.16 & 4.64 & 7.82 \\
\hline \multirow{2}{*}{$\begin{array}{l}\text { CAge of initiation among all } \\
\text { smokers (past and current) }\end{array}$} & Mean & 17.8 & 21.62 & 17.23 & 21.64 & 18.66 & 20.47 & 19.46 & 19.77 & 18.58 & 19.37 & 18.15 & 19.42 \\
\hline & SD & 3.69 & 10.08 & 4.11 & 10.4 & 6.35 & 10.14 & 5.36 & 6.78 & 4.47 & 4.75 & 4.99 & 7.49 \\
\hline \multirow{3}{*}{$\begin{array}{l}\text { वCurrent smokers advised } \\
\text { by an MD to stop smoking }\end{array}$} & $n$ (\%) & $17(34.00)$ & $12(37.50)$ & $6(23.08)$ & $24(66.67)$ & $16(47.06)$ & $11(34.37)$ & $9(69.23)$ & $7(53.85)$ & $16(36.36)$ & $2(25.00)$ & $6(23.08)$ & $9(75.00)$ \\
\hline & $95 \% \mathrm{Cl}$ & 20.87 & 20.73 & 6.88 & 51.27 & 30.28 & 17.92 & 44.14 & 26.75 & 22.15 & -5.01 & 6.88 & 50.5 \\
\hline & $95 \% \mathrm{Cl}$ & 47.13 & 54.27 & 39.27 & 82.07 & 63.84 & 50.83 & 94.32 & 80.95 & 50.58 & 55.01 & 39.27 & 99.5 \\
\hline \multirow{3}{*}{ 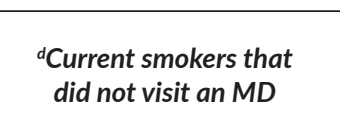 } & n (\%) & $23(46.00)$ & $7(21.87)$ & $8(30.77)$ & $7(19.44)$ & $8(23.53)$ & $14(43.75)$ & $2(15.38)$ & $3(23.08)$ & $6(13.64)$ & $1(12.50)$ & $16(61.54)$ & $1(8.33)$ \\
\hline & $95 \% \mathrm{Cl}$ & 32.18 & 7.55 & 13.03 & 6.52 & 9.27 & 26.56 & -4.23 & 0.17 & 3.5 & -10.42 & 42.84 & -7.30 \\
\hline & $95 \% \mathrm{Cl}$ & 59.81 & 36.20 & 48.51 & 32.37 & 37.79 & 60.94 & 35 & 45.98 & 23.78 & 35.42 & 80.24 & 23.97 \\
\hline
\end{tabular}


Table 3. Prevalence of hypertension and the mean systolic and diastolic measurements among the respondents

\begin{tabular}{|c|c|c|c|c|c|c|c|c|c|c|c|c|c|}
\hline \multirow{3}{*}{ Risk factor } & \multirow{3}{*}{$\mathrm{N}$} & \multicolumn{5}{|c|}{ Barangay } & \multicolumn{7}{|c|}{ Barangay } \\
\hline & & Anuling Cerca 1 & Anuling Cerca 2 & Banaba Cerca & Lumipa & Palocpoc 1 & Palocpoc 2 & Pangil & Panungyan 1 & Panungyan 2 & Pob 4 & Sulsugin & Talon \\
\hline & & 180 & 140 & 126 & 132 & 148 & 160 & 66 & 110 & 185 & 48 & 121 & 109 \\
\hline \multirow{3}{*}{ 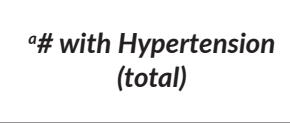 } & $n(\%)$ & $47(26.11)$ & $29(20.71)$ & $44(34.92)$ & $42(31.82)$ & $39(26.35)$ & $63(39.37)$ & $26(39.39)$ & $30(27.27)$ & $59(31.89)$ & $21(43.75)$ & $40(33.06)$ & $50(45.87)$ \\
\hline & $95 \% \mathrm{Cl}$ & 19.69 & 14 & 26.6 & 23.87 & 19.25 & 31.8 & 27.6 & 18.95 & 25.18 & 29.72 & 24.68 & 36.52 \\
\hline & $95 \% \mathrm{Cl}$ & 32.53 & 27.43 & 43.24 & 39.76 & 33.45 & 46.95 & 51.18 & 35.6 & 38.61 & 57.78 & 41.44 & 55.23 \\
\hline \multirow{3}{*}{$\begin{array}{l}\text { Previously diagnosed } \\
\text { hypertensives, } \\
\text { on medication }\end{array}$} & $n(\%)$ & $34(72.34)$ & $23(79.31)$ & $20(45.45)$ & $22(52.38)$ & $27(69.23)$ & $46(73.02)$ & $13(50.00)$ & $23(76.67)$ & $44(74.58)$ & $15(71.43)$ & $21(52.50)$ & $35(70.00)$ \\
\hline & $95 \% \mathrm{Cl}$ & 59.55 & 64.57 & 30.74 & 37.28 & 54.74 & 62.05 & 30.78 & 61.53 & 63.46 & 52.11 & 37.02 & 57.3 \\
\hline & $95 \% \mathrm{Cl}$ & 85.13 & 94.05 & 60.17 & 67.49 & 83.72 & 83.98 & 69.22 & 91.8 & 85.69 & 90.75 & 67.98 & 82.7 \\
\hline \multirow{3}{*}{${ }^{\circ A}$ Also with diabetes } & $n(\%)$ & $9(5.00)$ & $1(0.71)$ & $6(4.76)$ & $7(5.30)$ & $6(4.05)$ & $10(6.25)$ & $8(12.12)$ & $5(4.54)$ & $9(4.86)$ & $5(10.42)$ & $0(0)$ & $7(6.42)$ \\
\hline & $95 \% \mathrm{Cl}$ & 1.82 & -0.68 & 1.04 & 1.48 & 0.88 & 2.5 & 4.25 & 0.65 & 1.76 & 1.77 & 0 & 1.82 \\
\hline & $95 \% \mathrm{Cl}$ & 8.18 & 2.11 & 8.48 & 9.13 & 7.23 & 10 & 19.99 & 8.44 & 7.96 & 19.06 & 0 & 11.02 \\
\hline \multirow{2}{*}{$\begin{array}{c}\text { 'Mean systolic BP } \\
\text { (all study participants) }\end{array}$} & Mean & 124.83 & 117.44 & 126.35 & 125.15 & 121.16 & 125.08 & 126.67 & 119.44 & 124.5 & 126.19 & 121.54 & 126.31 \\
\hline & SD & 21.04 & 18.91 & 21.15 & 23.23 & 20.22 & 20.64 & 20.17 & 20 & 21.36 & 20.71 & 18 & 21.04 \\
\hline \multirow{2}{*}{$\begin{array}{c}\text { cMean diastolic BP } \\
\text { (all study participants) }\end{array}$} & Mean & 80.34 & 77.18 & 83.58 & 79.62 & 77.21 & 81.28 & 81.93 & 78.13 & 80.41 & 81.61 & 80.51 & 81.67 \\
\hline & SD & 11.91 & 11.66 & 13.15 & 11.79 & 12.32 & 13.47 & 10.16 & 10.18 & 13.43 & 11.69 & 10.34 & 12.27 \\
\hline
\end{tabular}

Table 4. Prevalence of diabetes mellitus and the mean CBG values among the respondents

\begin{tabular}{|c|c|c|c|c|c|c|c|c|c|c|c|c|c|}
\hline \multirow{3}{*}{ Risk factor } & \multirow{3}{*}{$\mathrm{N}$} & \multicolumn{5}{|c|}{ Barangay } & \multicolumn{7}{|c|}{ Barangay } \\
\hline & & Anuling Cerca 1 & Anuling Cerca 2 & Banaba Cerca & Lumipa & Palocpoc 1 & Palocpoc 2 & Pangil & Panungyan 1 & Panungyan 2 & Pob 4 & Sulsugin & Talon \\
\hline & & 180 & 140 & 126 & 132 & 148 & 160 & 66 & 110 & 185 & 48 & 121 & 109 \\
\hline \multirow{3}{*}{$\begin{array}{l}\text { o\# with Diabetes } \\
\text { Mellitus (total) }\end{array}$} & $n(\%)$ & $14(7.78)$ & $3(2.14)$ & $10(7.94)$ & $11(8.33)$ & $12(8.11)$ & $14(8.75)$ & $9(13.64)$ & $8(7.27)$ & $17(9.19)$ & $9(18.75)$ & $3(2.48)$ & $11(10.09)$ \\
\hline & $95 \% \mathrm{Cl}$ & 3.86 & -0.26 & 3.22 & 3.62 & 3.71 & 4.37 & 5.36 & 2.42 & 5.03 & 7.71 & -0.29 & 4.44 \\
\hline & $95 \% \mathrm{Cl}$ & 11.69 & 4.54 & 12.66 & 13.05 & 12.51 & 13.13 & 21.92 & 12.13 & 13.35 & 29.79 & 5.25 & 15.75 \\
\hline \multirow{3}{*}{$\begin{array}{l}\text { Previously diagnosed } \\
\text { diabetics, on medication }\end{array}$} & $n$ (\%) & 10 (71.43) & $3(100)$ & $6(60.00)$ & 8 (72.73) & $7(58.33)$ & $10(71.43)$ & $6(66.67)$ & $3(37.50)$ & $13(76.47)$ & $6(66.67)$ & $2(66.67)$ & $8(72.73)$ \\
\hline & $95 \% \mathrm{Cl}$ & 47.76 & 100 & 29.64 & 46.41 & 30.44 & 47.76 & 35.87 & 3.95 & 56.31 & 35.87 & 13.32 & 46.41 \\
\hline & $95 \% \mathrm{Cl}$ & 95.09 & 100 & 90.36 & 99.05 & 86.23 & 95.09 & 97.46 & 71.05 & 96.63 & 97.46 & 120.01 & 99.05 \\
\hline \multirow{2}{*}{$\begin{array}{c}\text { DMean fasting CBG } \\
\text { (all study participants) }\end{array}$} & Mean & 89.71 & 79.03 & 91.14 & 85.5 & 90.09 & 89.42 & 90.1 & 83.5 & 83.53 & 85.03 & 79.66 & 85.78 \\
\hline & SD & 33.87 & 17.84 & 35.78 & 42.13 & 36.94 & 26.66 & 46.18 & 21.91 & 27.65 & 25.98 & 18.16 & 30.31 \\
\hline \multirow{3}{*}{$\begin{array}{l}\text { \#\# of participants with } \\
\text { fasting CBG }>126 \mathrm{mg} / \mathrm{dl}\end{array}$} & $n$ (\%) & $10(8.06)$ & $2(1.98)$ & $8(13.56)$ & $5(4.95)$ & $9(7.09)$ & $7(5.60)$ & $3(10.00)$ & $4(4.54)$ & $5(3.85)$ & $2(6.25)$ & $2(2.17)$ & $7(6.86)$ \\
\hline & $95 \% \mathrm{Cl}$ & 3.27 & -0.74 & 4.82 & 0.72 & 2.62 & 1.57 & -0.73 & 0.19 & 0.54 & -2.14 & -0.81 & 1.96 \\
\hline & $95 \% \mathrm{Cl}$ & 12.86 & 4.7 & 22.29 & 9.18 & 11.55 & 9.63 & 20.73 & 8.9 & 7.15 & 14.64 & 5.15 & 11.77 \\
\hline \multirow{3}{*}{$\begin{array}{l}\text { C\# of participants with } \\
\text { fasting CBG >100 mg/dl }\end{array}$} & & $22(17.74)$ & $6(5.94)$ & $11(18.64)$ & 11 (10.89) & 18 (14.17) & $26(20.80)$ & $4(13.33)$ & $11(12.50)$ & 19 (14.61) & $5(15.62)$ & $6(6.52)$ & $13(12.74)$ \\
\hline & $95 \% \mathrm{Cl}$ & 11.02 & 1.33 & 8.71 & 4.81 & 8.11 & 13.68 & 1.17 & 5.59 & 8.54 & 3.04 & 1.48 & 6.27 \\
\hline & $95 \% \mathrm{Cl}$ & 24.47 & 10.55 & 28.58 & 16.97 & 20.24 & 27.91 & 25.5 & 19.41 & 20.69 & 28.21 & 11.57 & 19.22 \\
\hline
\end{tabular}

2013 and 2015 FNRI surveys, there was a wide variability seen in the results across the 12 barangays. The wide $90 \%$ ) may explain this phenomenon, where people with existing risk factors may have been overrepresented in the areas with low participation. The wide variability in the rate of tobacco use across the barangays can be explained by this variability in the participation rate. If we consider only those barangays where the response rate was more than $80 \%$ ( 5 barangays), the mean proportion of current smokers would be $25.57 \%$, similar to the 2015 national prevalence of $25.3 \%$. Though the proportion of current smokers seemed comparable to the national average, the rate of passive smoking seen in our study was very high (60-80\%) compared to the national prevalence of $36.4 \%$. This deserves attention

and should be addressed by health planners through a more aggressive and vigorous campaign to not only minimize but se altogether.

In 2015, the national proportion of current adult drinkers or those who drank in the 30 days before they were interviewed was $44.9 \%$, much higher than the weighted mean of current drinkers in the 12 barangays we studied (31.43\%). However, among these current drinkers, the proportion of $54.9 \%$ ). Our study also showed that most of the people in our barangays consumed sufficient servings of fruits and/ regetables on an average day compared to the national mean. More or less half of the people who participated
in our study were able to eat the recommended amount $(5$ servings or around $400 \mathrm{~g}$ ) of fruits and/or vegetables on an average day, though most of them were unable to eat both of Filipinos were reported to be unable to eat a minimum of 5 servings of fruits and/or veretable servings on an average 5 servings of find hondor day. Considering, however, that a significant proportion of our
respondents were farmers, many of them fruit and/or vegetable farmers, we were surprised that only around half of them ate sufficient amounts of these food items on an average day. Again, as opposed to the FNRI report that $42.5 \%$ of Filipino were physically inactive, respondents in our study were generally physically active since most of them were farmers. The FNRI surveys did not make a diagnosis of hypertension in the survey since most of the BP measurement were taken on a single visit. The reference hypertension prevalence figure we used here came from the report of the Presyon 3 national survey conducted by the Council of Hypertension in 2013 where the prevalence of hypertension was estimated to be at $28 \% .^{16}$ The mean hypertension prevalence in the 5 barangays with good participation rates was a little higher at $\sim 30 \%$. The proportion in our study of those we considered as having diabetes mellitus either from history or from the fasting CBG measurement was $7.93 \%$, a diabetes prevalence of $5.8 \%$ in the Philippines.

Overall, our research revealed significant findings that health policy makers of the AMIGA municipalities should consider. First is the high rate of passive smoking in the area. Though the smoking prevalence seen in the study was comparable to the national average, there seemed to be more 
Table 5. Prevalence of obesity and the proportion of respondents with blood cholesterol levels above $200 \mathrm{mg} / \mathrm{dl}$ and $240 \mathrm{mg} / \mathrm{dl}$

\begin{tabular}{|c|c|c|c|c|c|c|c|c|c|c|c|c|c|}
\hline \multirow{3}{*}{ Risk factor } & \multirow{3}{*}{$\mathrm{N}$} & \multicolumn{5}{|c|}{ Barangay } & \multicolumn{7}{|c|}{ Barangay } \\
\hline & & Anuling Cerca 1 & Anuling Cerca 2 & Banaba Cerca & Lumipa & Palocpoc 1 & Palocpoc 2 & Pangil & Panungyan 1 & Panungyan 2 & Pob 4 & Sulsugin & Talon \\
\hline & & 124 & 108 & 62 & 99 & 130 & 127 & 31 & 88 & 130 & 31 & 90 & 102 \\
\hline \multirow{3}{*}{ 'ODese by BMI } & $n(\%)$ & $50(40.32)$ & $44(40.74)$ & $18(29.03)$ & $46(46.46)$ & $53(40.77)$ & $58(45.67)$ & $11(35.48)$ & $44(50.00)$ & $51(39.23)$ & $16(51.61)$ & $40(44.44)$ & $53(51.96)$ \\
\hline & $95 \% \mathrm{Cl}$ & 31.69 & 31.47 & 17.73 & 36.64 & 32.32 & 37.01 & 18.64 & 39.55 & 30.84 & 34.02 & 34.18 & 42.26 \\
\hline & $95 \% \mathrm{Cl}$ & 48.96 & 50.01 & 40.33 & 56.29 & 49.22 & 54.33 & 52.33 & 60.45 & 47.62 & 69.2 & 54.71 & 61.66 \\
\hline \multirow{3}{*}{ DObese by waist circumference } & $n(\%)$ & $62(50.00)$ & $57(53.27)$ & $26(41.93)$ & $49(50.00)$ & $60(46.51)$ & $69(54.33)$ & $20(62.50)$ & $38(43.18)$ & $59(45.04)$ & $21(43.75)$ & $42(34.43)$ & $61(55.96)$ \\
\hline & $95 \% \mathrm{Cl}$ & 41.20 & 43.82 & 29.65 & 40.1 & 37.90 & 45.67 & 45.73 & 32.83 & 36.52 & 29.72 & 25.99 & 46.64 \\
\hline & $95 \% \mathrm{Cl}$ & 58.80 & 62.72 & 54.22 & 59.9 & 55.12 & 62.99 & 79.27 & 53.53 & 53.56 & 57.78 & 42.86 & 65.28 \\
\hline \multirow{3}{*}{$\begin{array}{c}\text { CObese by } \\
\text { waist-to-hip ratio }\end{array}$} & $n(\%)$ & $62(50.00)$ & $62(57.94)$ & $34(54.84)$ & $65(66.33)$ & $66(51.16)$ & $62(48.82)$ & $25(78.12)$ & $43(49.42)$ & $57(43.85)$ & $20(41.67)$ & $53(43.44)$ & $63(57.80)$ \\
\hline & $95 \% \mathrm{Cl}$ & 41.20 & 48.59 & 42.45 & 56.97 & 42.54 & 40.12 & 63.8 & 38.92 & 35.32 & 27.72 & 34.65 & 48.53 \\
\hline & $95 \% \mathrm{Cl}$ & 58.80 & 67.3 & 67.23 & 75.68 & 59.79 & 57.51 & 92.45 & 59.93 & 52.38 & 55.61 & 52.24 & 67.07 \\
\hline \multirow{3}{*}{$\begin{array}{c}{ }^{d C} \text { Cholesterol level } \\
>240 \mathrm{mg} / d \mathrm{ll}\end{array}$} & $n(\%)$ & $27(22.13)$ & $9(8.49)$ & $6(10.53)$ & $13(13.26)$ & $23(17.97)$ & $14(11.20)$ & $7(23.33)$ & $13(14.94)$ & $21(16.15)$ & 9 (28.12) & $16(17.39)$ & $20(19.61)$ \\
\hline & $95 \% \mathrm{Cl}$ & 14.76 & 3.18 & 2.56 & 6.55 & 11.32 & 5.67 & 8.20 & 7.45 & 9.83 & 12.55 & 9.65 & 11.90 \\
\hline & $95 \% \mathrm{Cl}$ & 29.50 & 13.80 & 18.49 & 19.98 & 24.62 & 16.73 & 38.47 & 22.43 & 22.48 & 43.70 & 25.14 & 27.31 \\
\hline \multirow{3}{*}{$\begin{array}{c}{ }^{\mathrm{d} C h o l e s t e r o l ~ l e v e l ~} \\
>200 \mathrm{mg} / \mathrm{dl}\end{array}$} & $n(\%)$ & $74(60.66)$ & $42(39.62)$ & $27(47.37)$ & $41(41.84)$ & 65 (50.78) & $44(35.20)$ & $17(56.67)$ & $42(48.28)$ & $56(43.08)$ & $18(56.25)$ & $41(44.56)$ & $52(50.98)$ \\
\hline & $95 \% \mathrm{Cl}$ & 51.99 & 30.31 & 34.41 & 32.07 & 42.12 & 26.83 & 38.93 & 37.77 & 34.56 & 39.06 & 34.41 & 41.28 \\
\hline & $95 \% \mathrm{Cl}$ & 69.32 & 48.93 & 60.33 & 51.6 & 59.44 & 43.57 & 74.40 & 58.78 & 51.59 & 73.44 & 54.72 & 60.68 \\
\hline
\end{tabular}

$\mathrm{N}=1527$; ${ }^{\circ}$ Missing data $n=405 ;{ }^{\circ}$ missing data $n=350 ;{ }^{c}$ missing data $n=352 ;{ }^{\circ}$ missing data $n=418$

non-smokers affected by tobacco use in the study area than in the country in general. None of the AMIGA municipalities has so far sustained an anti-smoking program. This finding could provide an impetus for one, but it would be more prudent to prioritize the setting up of safety measures to protect the non-smokers from the effects of tobacco in the area. Further, the anti-smoking campaign should involve the male population and those in the younger age groups. Second is the high proportion of people with obesity using all three parameters of BMI, waist circumference and waistto-hip ratio relative to the national average, particularly among women. This is despite the good intake of fruits and vegetables and the allocation of more than the required time and type of physical activities. The high proportion of respondents with elevated blood cholesterol may signify a fatrich diet among the population in the area. The diet should therefore, be fhe AMIGA has of the entort on ifsestyle modifcation in the Zumba ano co wome The fings of this study might help them redirect their efforts towards diet modification The third parameter is the high proportion of binge drinkers seen in the study. Binge drinking, especially a on males, has traditionally been accepted in rural communities becuses of the perception of the macho image that ooes with the practice. However, the high rate of accidents and the the lasting effect on the health of the binge drinker should be discussed more, and measures should be instituted to decrease the average consumption and number of drinking days of these drinkers. Fourth is the relatively higher proportion of individuals with hypertension and diabetes seen in our study. Those who were seen to have elevated blood pres never been diagnosed as such prior to the study should be reexamined and verified if they indeed have hypertension.

However, the mean systolic and diastolic blood pressures in the area were also seen to be relatively higher than the thtional average and this might indicate a higher tendency the population in the area for hypertension.

Limitations

The results of this study cannot be generalized to the entire populations of the AMIGA municipalities since the barangays were chosen purposively. The research results from the barangays with more than $80 \%$ response rate may reflect a in some of the barangays was a big limitation in this study.

\section{CONCLUSION}

The study showed that there is a relatively high prevalence of risk factors of NCDs in the 12 barangays of the AMIGA and diabetes. Since there is an and diseses sice there is an ongoing program that research provide the basine aginst which the stecess or failure of this program can be measured.

Note

The results of this research, as well as this author's ecommendations have been presented and submitted to the local health authorities and municipal executive of the AMIGA municipalities.

\section{Acknowledgments}

The support and assistance of the Municipal Health Officers, Rural Health Unit staff, and Barangay Health Workers of the AMIGA municipalfites were vital in the implementation of this study. The help provided by the students, FCM residents, and the faculty and staff of the UPM CHDP was likewise invaluable. Sample size computation was done by Professor Jesus Sarol and Dr. Amiel Bermudez of the UPM College of Public Health. Data presentation an statistical analyses were done by Ms. Clarisse Julian Pangilinan of the UP NIH Institute of Pharmaceutical Sciences and Mr. Alvin Tan of the Research Institute of Tropical Medicine.

\section{Statement of Authorship}

The author participated in all aspects of the research - data collection and analysis, and completion of the fina version submitted.

\section{Author Disclosure}

The author declared no conflicts of interest.

Funding Source

This paper was funded by the Research and Inplenter College of Medicine under Dean Agnes Meji.

\section{REFERENCES}

World Health Organization. Global status report on noncommunicable diseases 2014. Geneva: World Health Organization; 2014. p. xi World Health Organization. Global Health Observatory (GHO) Data $\mathrm{gho/ncd/mortality \_ morbidity/en/}$ World Health Organization. Noncommunicable disease and poverty:
the need for pro-poor strategies in the Western Pacific Region: a the need for pro-poor strategies in the Western Pacific Region:
review. Geneva: World Health Organization; 2006. p.vii. review. Geneva: World Health Organization, 2006. p.vili.
World Health Organization. Noncommunicable diseases (NCD) country profiles [Internet] 2014 [cited 2018 May]. Available from hittp://wwww.who.int/nmh//countries/phl_en.pdf
Philippine Statistics Authority 2016 Philippines Statistical Yearbook Philippine Statistics Authority. 2016 Philippines Statistical Yearboo
Quezon City: Philippine Statistics Authority 2016.
Food and Nutrition Research Institute. Philippine Nutrition Facts and Figures 2013: 8th National Nutrition Survey (Clinical and Health
Survey). Bicutan, Taguig: Food and Nutrition Research Institute, , et.al. The World Health Organization STEPwise approach to noncommunicable risk-factor surveillance: methods, challenges and opportunities. Am J Palth Hati. 2016 Jan; 1066 (1):74-8
Department of Health National Health Objectives. Manilat

Department of Health; 2011. p. 15 .
World Health Organization. The WHO STEPwise approach to 5

World Health Organization. The WHO STEPwise approach to Health disease risk factor surveillance
Dangazation; 2008. p.2-1-9

plic of the Philippines. Operations manual on the Philippine Package of Essential NCD Interventions (PHIL PEN) on the integrated management of hypertension and diabetes

for primary health care facilities. Manila: DOH; 2012. p. 20-33.
World Heatth Diseases Department. Global Physical Activity Questionnnaire: Analysis Guide. Geneva: WHO; 2002. pp. 2-3. US Department of Health and Human Services. The 7 th report of the Joint National Committee on Prevention, Detection, Evaluation and
Treatment of High Blood Pressure. Bethesda, MD: US Government Printing Office; 2003. p. 3.

14. James PA, Oparil S, Carter BL, Cushman WC, Dennison-Himmelfarb C, Handler J, et al. 2014 evidence-based guideline for the management appointed to the eighth Joint National Committee (JNC8). JAMA. $2014 \mathrm{Feb} ; 311(5): 507-20$.

and Nutrition Research Institute. Philippine Nutrition Facts nd Figures 2015: Clincical Ind Health Survey. Bicutan, Taguig:
Food and Nutritition Research Institute, Departent of Science and Technology; 2016. pp. 1-3.

Sison JA. Presyon 3: Report of the Council on Hypertension [Internet]. W

World Health Organization. Diabetes Country Profiles [Internet]. World Health Organization. Diabetes Country Profiles [Internet]]
cited 2018 Mayal. Available from: http://wwww.who.int/diabetes 